\title{
Numerical analysis of thin torispherical end closures
}

DOI:

10.1016/S0308-0161(96)00062-2

\section{Document Version}

Accepted author manuscript

Link to publication record in Manchester Research Explorer

\section{Citation for published version (APA):}

Tafreshi, A. (1997). Numerical analysis of thin torispherical end closures. International Journal of Pressure Vessels and Piping, 71(1), 77-88. https://doi.org/10.1016/S0308-0161(96)00062-2

\section{Published in:}

International Journal of Pressure Vessels and Piping

\section{Citing this paper}

Please note that where the full-text provided on Manchester Research Explorer is the Author Accepted Manuscript or Proof version this may differ from the final Published version. If citing, it is advised that you check and use the publisher's definitive version.

\section{General rights}

Copyright and moral rights for the publications made accessible in the Research Explorer are retained by the authors and/or other copyright owners and it is a condition of accessing publications that users recognise and abide by the legal requirements associated with these rights.

\section{Takedown policy}

If you believe that this document breaches copyright please refer to the University of Manchester's Takedown Procedures [http://man.ac.uk/04Y6Bo] or contact uml.scholarlycommunications@manchester.ac.uk providing relevant details, so we can investigate your claim.

\section{OPEN ACCESS}




\title{
NUMERICAL ANALYSIS OF THIN TORISPHERICAL END CLOSURES
}

\author{
Azam Tafreshi Division of Mechanical Engineering, \\ The Manchester School of Engineering \\ University of Manchester, UK \\ atafreshi@manchester.ac.uk
}

\begin{abstract}
A numerical analysis study using the finite element method has been carried out to investigate the design sensitivity of thin torispherical end pressure vessels. A detailed dimensional survey of a number of thin full-size production-quality torispherical ends has shown that actual dimensions may differ significantly from nominal dimensions. The sensitivity of the end stresses to particular forms of shape imperfections were analysed numerically and compared with those in the corresponding 'perfect' end which are presented here in more detail. The effect of these shape imperfections on buckling pressure is also investigated. The buckling pressure and stresses in a series of torispherical ends are evaluated to show the effect of variation of shape parameters in these ends. It is also shown that, for stainless steel ends, small displacement analysis agrees much better with the experimental results than do those given by the large displacement analysis.
\end{abstract}




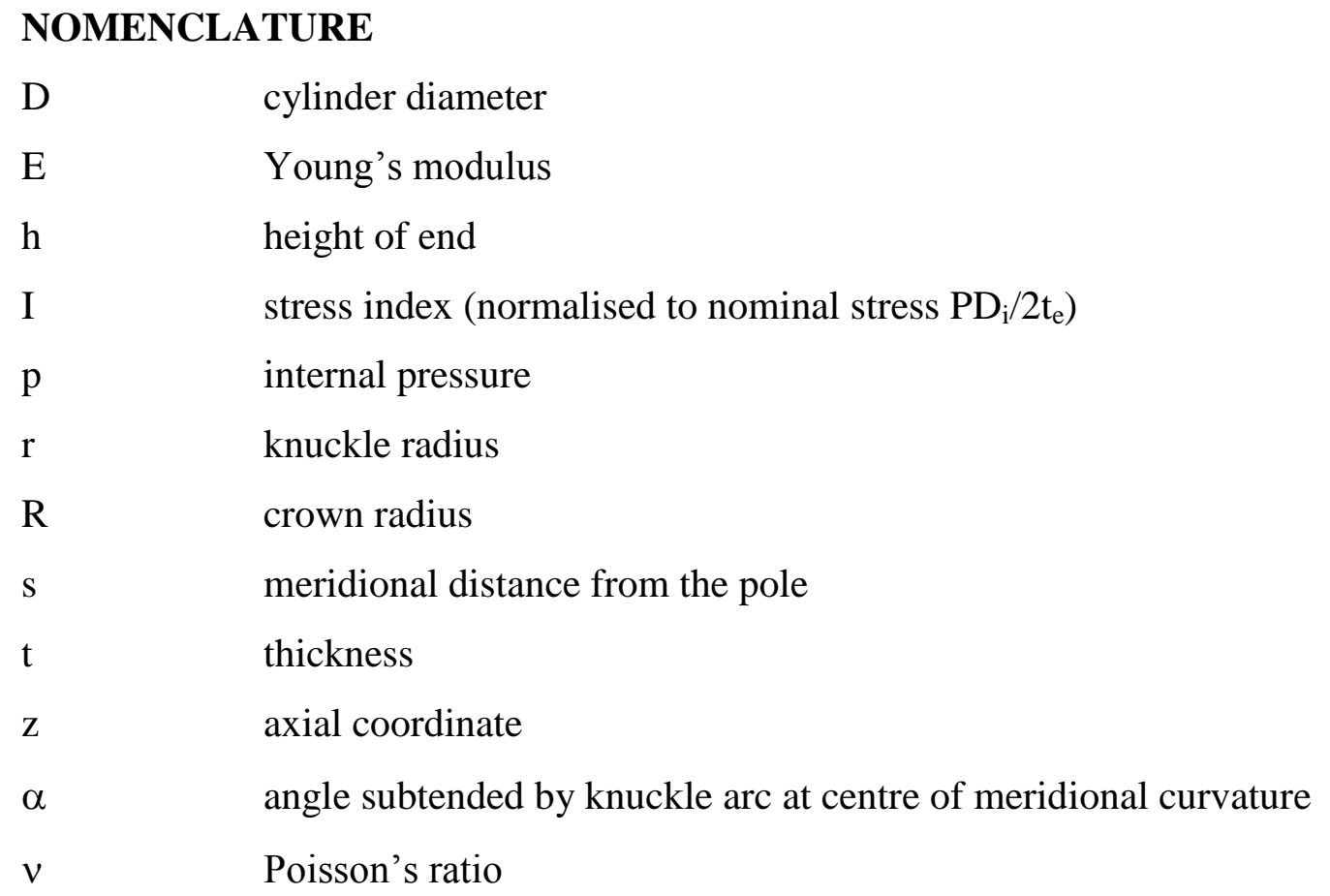

\section{Subscripts}

$\begin{array}{ll}\text { c } & \text { circumferential, cylinder } \\ \mathrm{e} & \text { end } \\ \mathrm{i} & \text { inner } \\ \mathrm{m} & \text { meridional } \\ \mathrm{o} & \text { outer }\end{array}$

\section{INTRODUCTION}

In a study by Tafreshi and Thorpe [1] the effect of shape and thickness imperfections on stress levels were investigated. Finite element models of thin-walled cylindrical pressure vessels with torispherical ends were developed in order to assess the effects of thickness and curvature variations on the peak stresses. With imperfections found in typical manufacturing procedures, stresses were shown to differ by a significant amount from those to be expected in perfectly formed vessels. The greatest changes were due to curvature variations, but the effects of thickness variations were also significant. However, the results of the work may provide information for a fatigue assessment analysis in predicting the actual stress values in the end. 
At sufficiently high yield stresses of the material, very thin shells are liable to loss of elastic stability. Stability problems of torispherical shells subjected to internal pressure were first studied by Mescall [2]. Soric [3] investigated the influence of geometric imperfections on the pre- and post-buckling behaviour of a thin torispherical shell subjected to internal pressure. Wunderlich et al. [4] studied the buckling behaviour and imperfection sensitivity of torispherical end closures under external pressure. Galletly [5] considered the buckling of fabricated torispherical shells, in which some simple approximate equations were used for predicting the buckling pressures of internally pressurised perfect torispherical ends.

In the present work, the finite element method (FEM) has been employed to investigate the effect of variation of shape parameters on critical buckling pressure and maximum stress of thin torispherical pressure vessels with perfect ends. The effect of manufacturing shape imperfections, such as thickness and curvature variations, on stresses and buckling pressure is also investigated. The results are compared with the corresponding experimental results $[6$, 7].

\section{TORISPHERICAL END PRESSURE VESSELS}

The end closures of pressurised cylinders are usually of torispherical type and sometimes hemispherical or ellipsoidal. Figure 1 reproduced from BS5500 shows the parameters used to define a torispherical end. The end dimensions-thickness, knuckle radius, crown radius and end height-can be non-dimensionalized with respect to the cylinder diameter. There are infinite combinations between a flat end $(R=\infty)$ and a hemisphere $(R+t=D / 2)$. Geometrically an end is completely defined by the thickness parameter (t/D) and any other two shape parameters $(\mathrm{r} / \mathrm{D}, \mathrm{R} / \mathrm{D}$ or $\mathrm{h} / \mathrm{D})$. The relation between these shape parameters is as follows: 


$$
\frac{r}{D}=\frac{\left(\frac{2 R}{D}-\frac{h}{D}\right) \frac{h}{D}-\frac{1}{4}}{\frac{2 R}{D}-1}
$$

Or

$$
\frac{h}{D}=\frac{R}{D}-\sqrt{\left(\frac{R}{D}\right)^{2}-\left[\frac{r}{D}\left(\frac{2 R}{D}-1\right)+0.25\right]}
$$

and the angle $(\alpha)$ subtended by the knuckle arc at the centre of meridional curvature can be obtained by the following equation

$$
\alpha=\arcsin \frac{\frac{h}{D}-\frac{R}{D}}{\frac{\left(\frac{2 R}{D}-\frac{h}{D}\right) \frac{h}{D}-\frac{1}{4}}{\frac{2 R}{D}-1}-\frac{R}{D}}
$$

These ends can be manufactured by various techniques, 'hot pressing', 'pressed and spun' and 'crown and segment'. More details on these techniques of manufacture may be found in Galletly and Moffat. The ends considered in this study are of 'pressed and spun' type, which are usually called 'spun' ends only.

The results of a detailed survey of the variations in crown curvature, knuckle curvature and thickness of 17 nominally torispherical pressure vessel ends were presented and discussed by Stanley and Campbell [9]. Six of the ends were of the 'crown and segment' construction; 11 were 'pressed and spun'. Table 1 shows the nominal dimensions of the 'pressed and spun' ends. To aid comparisons, the end numbers in Table 1 correspond to those of Stanley and Campbell [9]. It was shown that the crown curvature can increase locally to twice the nominal value, or more, and (again locally) can fall to zero or become negative. The knuckle 
curvature can approach twice or one half the nominal value over limited parts of the total knuckle arc length. Reductions in thickness may also be important, particularly in the knuckle region of spun ends; thickness reductions greater than $20 \%$ of the nominal value have been measured. Measured values, reproduced from Stanley and Campbell [11], of thickness and curvatures along meridians of ends 3, 4 and 5 are shown in Figs. 2 and 3, and for ends 8, 10 and 16 in Figs 4 and 5.

In order to calculate the real ends a FORTRAN computer program [1] was developed to read in the curvatures at a series of points on the ends and calculate their coordinates assuming there is a circular arc of the given curvature between any two adjacent points. For the best accuracy the chosen points were closely spaced. To maximize smoothness and prevent shape oscillation, spline fitting was used through the points [10, 11]. Ends 4, 8 and 16, with three different cylinder diameters, are selected for detail presentation. Ends 4 and 8 have the smallest and largest diameters, respectively. Figure 6 shows to scale the shapes of these ends with the curvature imperfections indicated in Figs 2 and 4, and also comparable perfect geometries.

\section{NUMERICAL ANALYSIS USING THE FINITE ELEMENT METHOD}

IDEAS [12] and ABAQUS [13], the CAD/CAE (computer aided design and engineering) packages, were used for finite element modelling and analysis, respectively. The analysis includes stress evaluation and buckling estimation of the torispherical end pressure vessels. 3node quadratic axi-symmetric shell elements, designated SAX2 in the ABAQUS Users' Manual, were used for modelling of torispherical ends under internal pressure. Although these are shell elements, they are also simple extensions of the beam elements designated B21 and B22 in the ABAQUS Users' Manual [13]. The extension is the addition of the 
circumferential stress components to the already existing meridional components. They are thus one-dimensional [13], deforming in a meridional plane. The axi-symmetric coordinates in this plane are $\mathrm{r}$ (radial) and $\mathrm{z}$ (axial) positions; degrees of freedom are radial and axial displacements and rotation in the rz plane.

For boundary conditions of the models analysed, the pole (point A in Fig. 1) was fixed in the radial direction, while point B was fixed in the axial direction. Since the stress variation is uniform along the cylinder, point B is selected 'remote' from the knuckle-cylinder junction where the stresses are highly nonlinear with respect to the $\mathrm{z}$ coordinate. Points A and B are also restrained against rotation in the rz plane. Figure 7 shows a typical perfect torispherical end together with the exaggerated deformed profile under internal pressure where the knuckle displaces inwards and the crown has the maximum displacement. For the analysis the mean dimensions of the end and cylinder were considered throughout because the elements lie on the shell middle surface.

For the ends with shape imperfections ABAQUS allows shell thicknesses to be specified at the nodes. This option simplifies the definition of non-constant shell thicknesses such as those found in composites, injection moulded components and pressure vessels. This way the real ends with thickness imperfections and curvature variations, as discussed above, were modelled. It should be mentioned that only imperfections in the meridional plane are considered and circumferential imperfection is ignored, so the models are assumed to be axisymmetric.

In the steel pressure vessels analysed by Tafreshi and Thorpe [1] best agreement with experimental results $[6,7]$ was obtained by assuming geometric linearity. This contrasted 
with the findings of Galletly and Moffat [8] who obtained better agreement by including geometric nonlinearities for aluminium pressure vessels. This is because of considerable difference in Young's modulus values between steel and aluminium, giving rise to smaller displacements in steel vessels. However, the higher stress values result from linear analysis so in order for the data to be more conservative, for the models analysed in the present work geometric linearity is assumed. Figure 8 shows inner surface meridional and outer surface circumferential stress indices for end 4 , considering linear and non-linear geometry for axisymmetric shell elements. It can be seen that the peak stresses are closer to the experimental results when geometric linearity is assumed.

In general, shell buckling analysis requires eigenvalue analysis to obtain estimates of the buckling mode and pressure. Assuming the response in the ends are elastic up to the estimated buckling pressure, by eigenvalue extraction [13] the elastic buckling pressure can be estimated. This assumption is typically useful for "stiff" structures, where the prebuckling response is almost linear. Figure 9 shows a typical plot of the first buckling mode of a torispherical end, which usually is the most critical one. It is assumed that the buckling mode is axi-symmetric. It can be seen that the maximum displacements occur at the pole. In general, critical buckling pressure can be reduced in the presence of shape imperfections. When no measured data concerning shape imperfections are available, imperfection sensitivity analysis may be carried out by assuming an imperfection in the original geometry of the ends, in the shape of buckling mode, and studying the effect of the magnitude of that imperfection on displacement response. 


\section{4. $\quad$ RESULTS}

Columns 2 and 3 of Table 2 show the peak outer surface circumferential $\left(I_{O c}\right)$ and inner surface meridional stress indices $\left(I_{i m}\right)$ for the ends of Table 1 with perfect geometries for the knuckle and crown calculated using FEM. These are normalized by the nominal circumferential stress in the cylinder. These stress indices could be compared with those experimental results [6-7] shown in columns 7 and 8 of Table 2. General speaking, $I_{O c}$ indices obtained experimentally are higher than numerical values with perfect ends. Except for ends 5 and 12, for which the differences between $I_{O c}$ values are within 0.1 and $6 \%$, for the rest of the models are within +21 and $+48 \%$. For $I_{i m}$ values the differences are within -24 and $+26 \%$.

Column 4 of Table 2 shows the critical buckling pressures of perfect ends of Table 1 obtained using the FEM. Column 9 of Table 2 shows the corresponding critical buckling pressures obtained experimentally [6,7]. The differences between numerical and those corresponding experimental values are within -29 and $+32 \%$, but in end 16 the difference is only $-5 \%$. Galletly [5] used simple approximate equations to predict the critical buckling pressures of perfect ends of Table 1 . In general, the predicted buckling pressures were $22-72 \%$ smaller than the experimental results [6-7], except for end 8 which the difference is only $3 \%$.

Table 3 shows the peak stress indices and buckling pressures of a series of torispherical pressure vessels with perfect ends obtained using the FEM. For these ends the nominal cylinder diameter is 54 in $(1371.6 \mathrm{~mm})$. The cylinder and end thickness parameters are $\mathrm{t}_{\mathrm{c}} / \mathrm{D}=$ 0.00193 and $t_{e} / D=0.00237$. The knuckle radius parameter $(r / D)$ varies from 0.04 to 0.111 while crown radius parameter (R/D) varies from 0.722 to 1.0. The results of Table 3 are plotted in Figs 10-12. Figures 10 and 11 show the variation of inner meridional stress index 
$\left(I_{i m}\right)$ with respect to knuckle radius (r/D) and crown radius (R/D), respectively. It can be seen that the higher knuckle radius is the lower stress index and vice versa. For a constant value of knuckle radius, the higher the crown radius is, the higher is the stress index. Figure 12 shows the effect of knuckle and crown radii on critical buckling pressure. This plot shows that for a constant value of crown radius the critical buckling pressure is independent of knuckle radius. For a constant value of knuckle radius, the higher the crown radius the lower the critical pressure.

For the distribution of circumferential and meridional stress indices of the inner and outer surfaces of the perfect end 3 refer to Stanley and Campbell [9]. Four different cases of end 3 were considered: (a) perfect end; (b) thickness variations of perfect profile; (c) curvature variations in end of uniform thickness; and (d) end with curvature and thickness variations. The indications of that study was that discrepancies in curvature have a considerably greater effect on stress levels than variations in thickness.

Columns 5 and 6 of Table 2 show the FE results [9] of ends 3, 4, 5, 10 and 16 with curvature and thickness variations shown in Figs 2-5. The inner surface meridional stress indices vary from values for perfect ends by -9 to $35 \%$. In comparison with experimental results the differences are within -6 and 17\%. Figures 13-15 show the distribution of inner surface meridional and outer surface circumferential stress indices of real and perfect ends 4, 8 and 16, respectively. Stress distribution trends of the real ends are similar to the perfect ends. However, there are fluctuations of stresses in the crown near the pole due to large variations of curvatures in this region. The differences of $+28 \%,-22 \%$ and $+24 \%$, for $I_{O c}$ indices, and $+34 \%$, $-9 \%$ and $+31 \%$, for $I_{i m}$ indices, can be observed in ends 4, 8 and 16, respectively. As shown in Fig. 6 the trend of the real 8 profile is different to ends 4 and 16. Perhaps this is the 
reason for lower stresses in real end 8 .

In Stanley and Campbell [6] the measured pole of end 9 is represented vs pressure. It is shown that in spite of the significant strain nonlinearities developed at lower pressures at some positions, the variation of deflection with pressure was practically linear up to the first buckling pressure. Fig. 16 shows pressure vs pole deflection and circumferential growth in cylinder for perfect and real ends 4, which is obtained numerically. It is assumed that the displacement response is linear up to the critical buckling pressure. It can be seen that for the same value of pressure the pole deflection is higher in the real end that the perfect end. The cylindrical growth is almost identical for the real and perfect ends.

\section{CONCLUSIONS}

Finite element models of thin walled cylindrical pressure vessels with torispherical ends have been developed in order to assess the effects of shape parameters on the peak stresses and critical buckling pressures. Eigenvalue analysis has been carried out to obtain estimates of the buckling pressures and modes, assuming the pre-buckling response is almost linear which is typical of stiff structures. Following the eigenvalue prediction, load-displacement analysis of the structure was carried out on perfect ends and ends with manufacturing shape imperfections to investigate imperfection sensitivity. It is clear that there is a distinction between the real and nominal dimensions of pressure vessel parts. It is understood that where these departures are exceeded the resulting effects on vessel stresses or stability will generally be significant. Finite element models of ends considering curvature and thickness imperfection were analysed and stresses were compared with the results of perfect ends and corresponding experimental results. It was shown that profile errors that are not immediately apparent nevertheless result in significant stress differences from design values. The 
numerical analyses were carried out on HP735, Cray EL98 and IBMRS6000 computers.

\section{ACKNOWLEDGEMENTS}

The author acknowledges the help of Professor P. Stanley of the Manchester School of Engineering in bringing the problem considered to her attention, and Dr T. E. Thorpe of the Manchester School of Engineering for his helpful discussions throughout the work.

\section{REFERENCES}

1. Tafreshi, A. and Thorpe, T. E., Effects of local departures from nominal dimensions on stresses in thin torispherical end closures. Journal of Strain Analysis, 1996, 31(4), 315-324.

2. Mescall, J., Stability of thin torispherical shells under uniform pressure. In Collected papers on Instability of Shell Structures. TN D-1510 NASA, 1962, pp. 671-92.

3. Soric, J., Elastic buckling of internally pressurised imperfect torispherical shells. Computational Mechanics, 1991, 8, 161-171.

4. Wunderlich, W., Rensch, H. J. and Obrecht, H., Analysis of elastic-plastic buckling and imperfection sensitivity of shells of revolution. In Proceedings of a State-of-the-Art Colloqium, ed. E. Ramm. Springer, Berlin, 1982, pp. 137-74.

5. Galletly, G. D., The buckling of fabricated torispherical shells under internal pressure. In Proceedings of a State-of-the-Art Colloqium, ed. E. Ramm. Springer, Berlin, 1982, pp. 429-66.

6. Stanley, P. and Campbell, T. D., Very thin torispherical pressure vessel ends under internal pressure: test procedure and typical results. Journal of Strain Analysis, 1981, $16,171-86$.

7. Stanley, P. and Campbell, T. D., Very thin torispherical pressure vessel ends under 
internal pressure: strains, deformations and buckling behaviour. Journal of Strain Analysis, 1981, 16, 187-200.

8. Galletly, G. D. and Moffat, D. G., Pressure Vessel Design: Concepts and Principles, Chap. 7, ed. J. Spence and A. S. Tooth. Spans, An imprint of Chapman \& Hall, 1994, pp. 245-89.

9. Stanley, P. and Campbell, T. D., Very thin torispherical pressure vessel ends: actual versus nominal dimensions. International Journal of Pressure Vessels and Piping, 1991, 46, 9-34.

10. Tafreshi, A. and Fenner, R. T., Design optimization using the boundary element method. Journal of Strain Analysis, 1991, 26, 231-41.

11. Tafreshi, A. and Fenner, R. T., Design sensitivity analysis using the boundary element method. Journal of Strain Analysis, 1993, 28, 283-91.

12. IDEAS (Integrated Design Engineering Analysis Software), Solid Modelling and Finite Element Modelling User's Manual. Structural Dynamics Research Corporation, USA, 1995.

13. ABAQUS User's Manual, Version 5.5. Hibbit, Karlson and Sorensen Inc., Providence, Rhode Island, 1995. 
Tafreshi, A. Apr. 1997 In : International Journal of Pressure Vessels and Piping. 71, 1, p. 77-88 12 p.

Table 1 End details : Nominal dimensions and shape parameters (1)

\begin{tabular}{||c|c|c|c|c|c||}
\hline \hline End No. & $\mathrm{D}$ in(mm) & $\mathrm{r} / \mathrm{D}$ & $\mathrm{R} / \mathrm{D}$ & $\mathrm{t}_{\mathrm{c}} / \mathrm{D}$ & $\mathrm{t}_{\mathrm{c}} / \mathrm{D}$ \\
\hline 3 & $54(1371.6)$ & 0.111 & 1.0 & 0.00237 & 0.00193 \\
\hline 4 & $54(1371.6)$ & 0.074 & 1.0 & 0.00237 & 0.00193 \\
\hline 5 & $54(1371.6)$ & 0.074 & 0.833 & 0.00237 & 0.00193 \\
\hline 6 & $54(1371.6)$ & 0.074 & 0.788 & 0.00237 & 0.00193 \\
\hline 8 & $108(2743.2)$ & 0.111 & 1.0 & 0.00119 & 0.00096 \\
\hline 9 & $108(2743.2)$ & 0.074 & 1.0 & 0.00119 & 0.00096 \\
\hline 10 & $108(2743.2)$ & 0.074 & 0.833 & 0.00119 & 0.00096 \\
\hline 11 & $108(2743.2)$ & 0.074 & 0.722 & 0.00119 & 0.00096 \\
\hline 12 & $108(2743.2)$ & 0.056 & 1.0 & 0.00119 & 0.00096 \\
\hline 16 & $81(2057.4)$ & 0.074 & 1.0 & 0.00158 & 0.00128 \\
\hline 17 & $81(2057.4)$ & 0.074 & 0.833 & 0.00158 & 0.00128 \\
\hline \hline
\end{tabular}




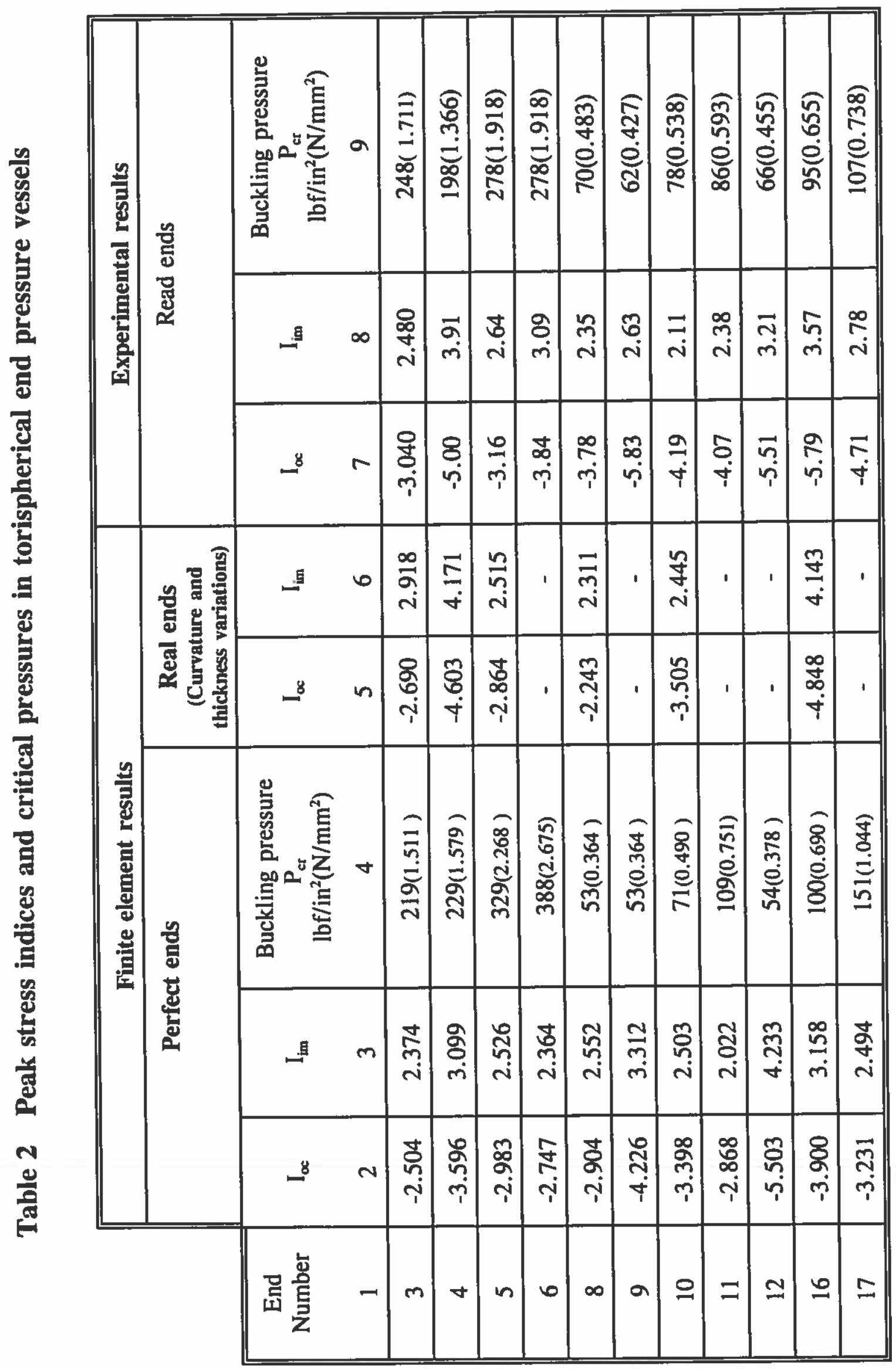


Tafreshi, A. Apr. 1997 In : International Journal of Pressure Vessels and Piping. 71, 1, p. 77-88 12 p.

Table 3 Peak stress indices and buckling pressure of a series of torispherical end pressure vessels(Finite element results)

$\left(\mathrm{D}=54 ", \mathrm{t}_{\mathrm{c}} / \mathrm{D}=\mathbf{0 . 0 0 1 9 3}, \mathrm{t}_{\mathrm{e}} / \mathrm{D}=\mathbf{0 . 0 0 2 3 7}\right)$

\begin{tabular}{|c|c|c|c|c|}
\hline $\mathbf{r} / \mathbf{D}$ & $\mathbf{R} / \mathbf{D}$ & $\mathbf{I}_{\mathrm{oc}}$ & $\mathbf{I}_{\mathbf{l m}}$ & $\underset{\mathrm{lbf} / \mathrm{in}^{2}\left(\mathbf{N} / \mathbf{m m}^{2}\right)}{\mathbf{P}_{\mathrm{er}}}$ \\
\hline \multirow[t]{4}{*}{0.04} & 1.0 & -5.493 & 5.312 & $199.36(1.375)$ \\
\hline & 0.833 & -5.491 & 4.500 & $286.57(1.977)$ \\
\hline & 0.788 & -4.217 & 4.310 & $319.07(2.201)$ \\
\hline & 0.722 & -3.728 & 3.961 & $380.04(2.621)$ \\
\hline \multirow[t]{4}{*}{0.056} & 1.0 & -4.606 & 4.088 & $199.39(1.375)$ \\
\hline & 0.833 & -3.823 & 3.464 & $285.76(1.971)$ \\
\hline & 0.788 & -3.578 & 3.318 & $319.085(2.201)$ \\
\hline & 0.722 & -3.201 & 3.106 & $381.552(2.632)$ \\
\hline \multirow[t]{4}{*}{0.074} & 1.0 & -3.596 & 3.099 & $199.60(1.377)$ \\
\hline & 0.833 & -2.983 & 2.600 & $285.44(1.969)$ \\
\hline & 0.788 & -2.747 & 2.364 & $320.84(2.213)$ \\
\hline & 0.722 & -2.646 & 2.305 & $380.50(2.625)$ \\
\hline \multirow[t]{4}{*}{0.1} & 1.0 & -2.80 & 2.561 & $198.98(1.372)$ \\
\hline & 0.833 & -2.277 & 1.957 & $285.39(1.968)$ \\
\hline & 0.788 & -2.142 & 1.805 & $319.30(2.202)$ \\
\hline & 0.722 & -1.934 & 1.654 & $381.14(2.629)$ \\
\hline \multirow[t]{4}{*}{0.111} & 1.0 & -2.504 & 2.374 & $198.62(1.370)$ \\
\hline & 0.833 & -1.999 & 1.775 & $286.29(1.975)$ \\
\hline & 0.788 & -1.877 & 1.668 & $319.08(2.201)$ \\
\hline & 0.722 & -1.689 & 1.487 & $382.01(2.635)$ \\
\hline
\end{tabular}


Tafreshi, A. Apr. 1997 In : International Journal of Pressure Vessels and Piping. 71, 1, p. 77-88 12 p.

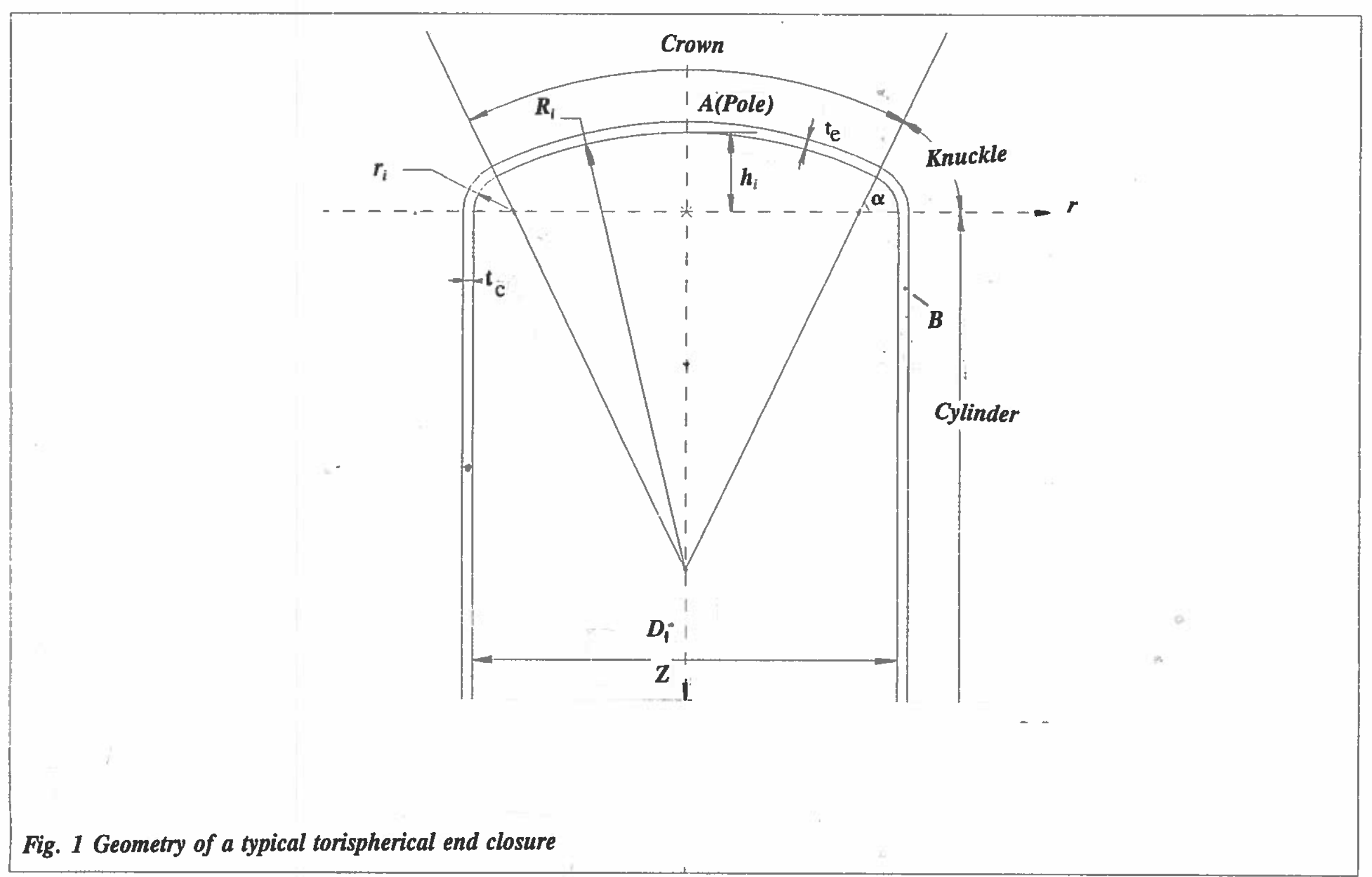




\section{Fig. 2 Curvature variations of ends 3, 4 and 5 (1)}

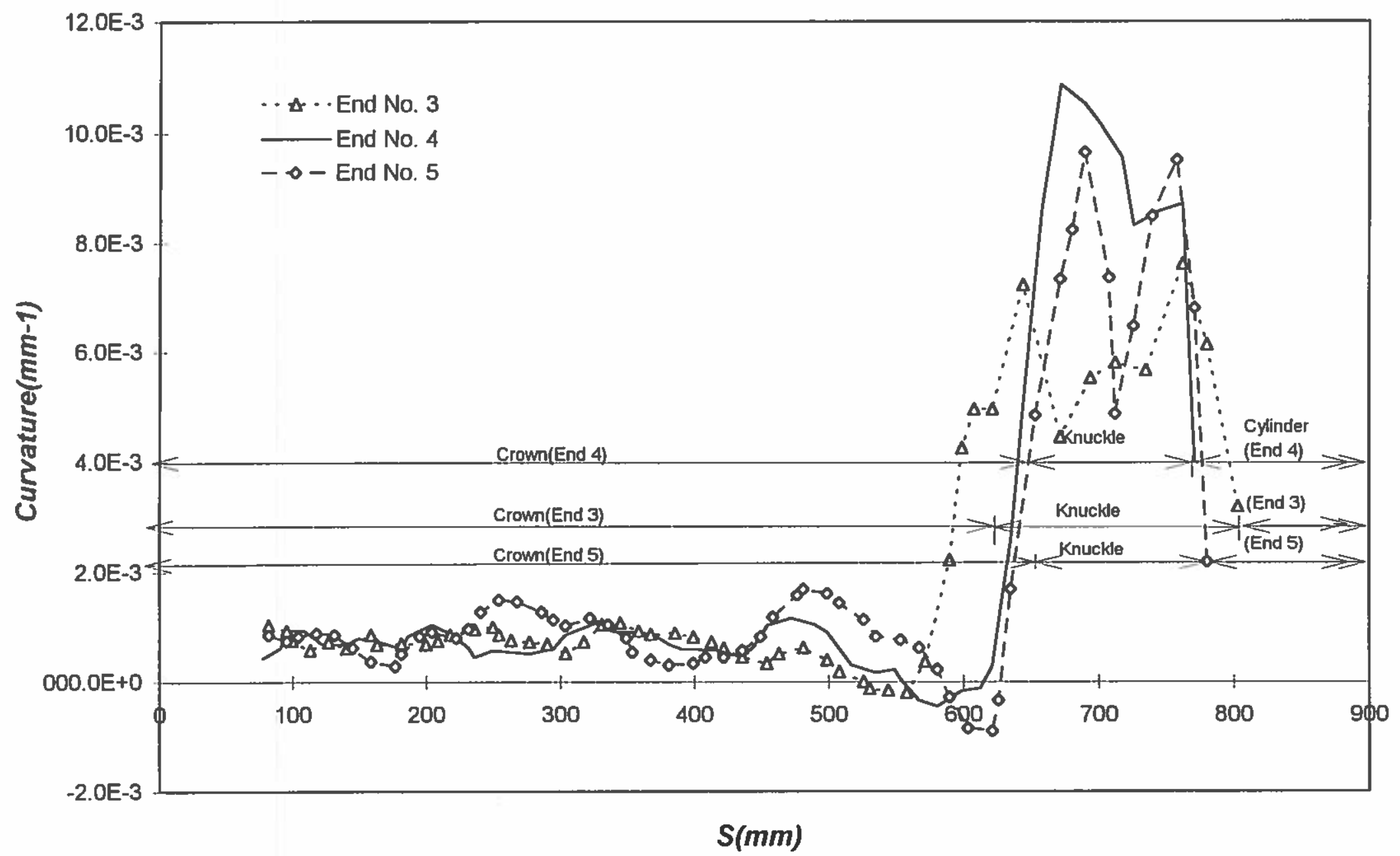


Tafreshi, A. Apr. 1997 In : International Journal of Pressure Vessels and Piping. 71, 1, p. 77-88 12 p.

Fig. 3 Thickness variations of ends 3, 4 and 5 (1)

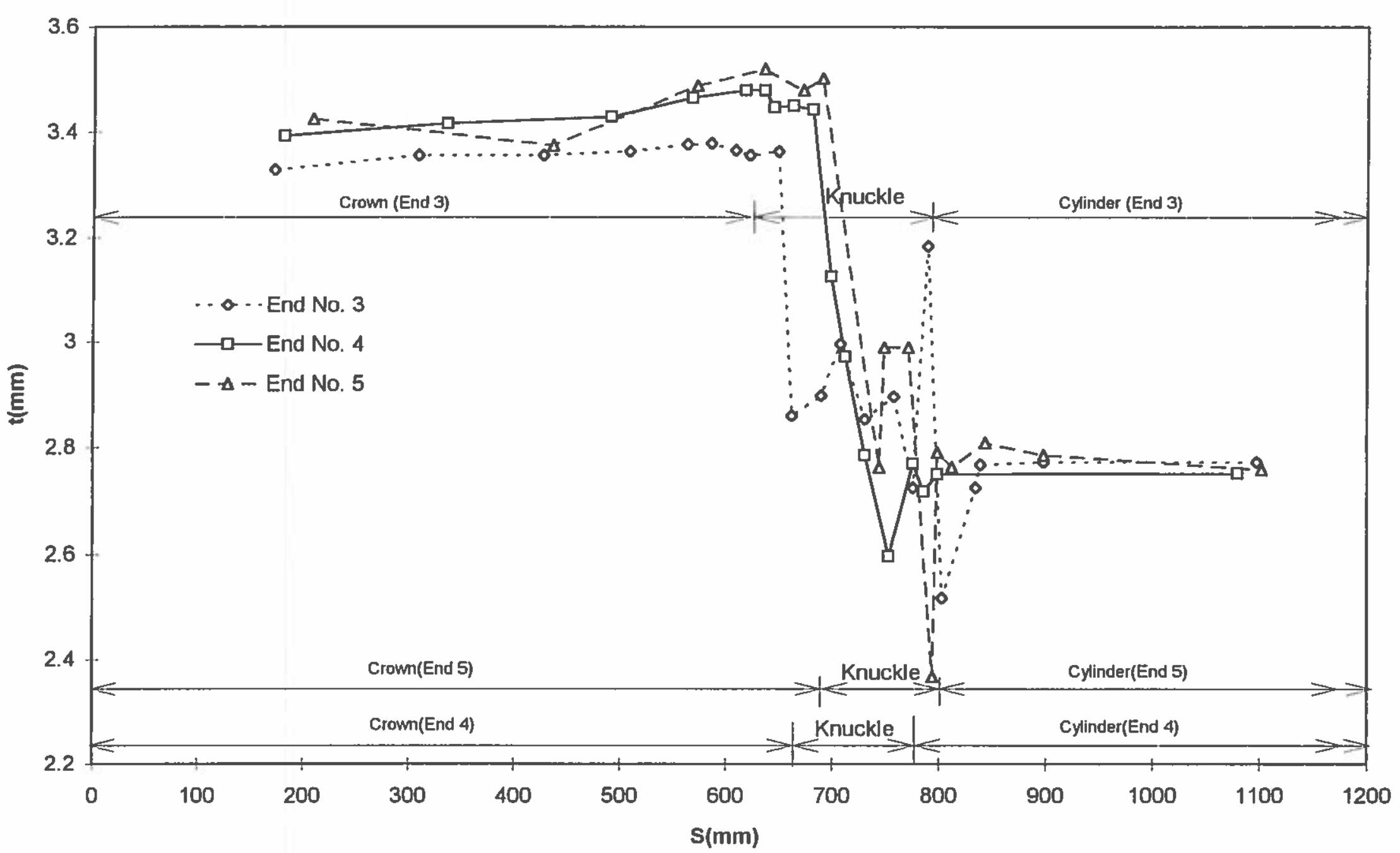


Tafreshi, A. Apr. 1997 In : International Journal of Pressure Vessels and Piping. 71, 1, p. 77-88 12 p.

Fig. 4 Curvature variations of ends 8, 10 and 16 (1)

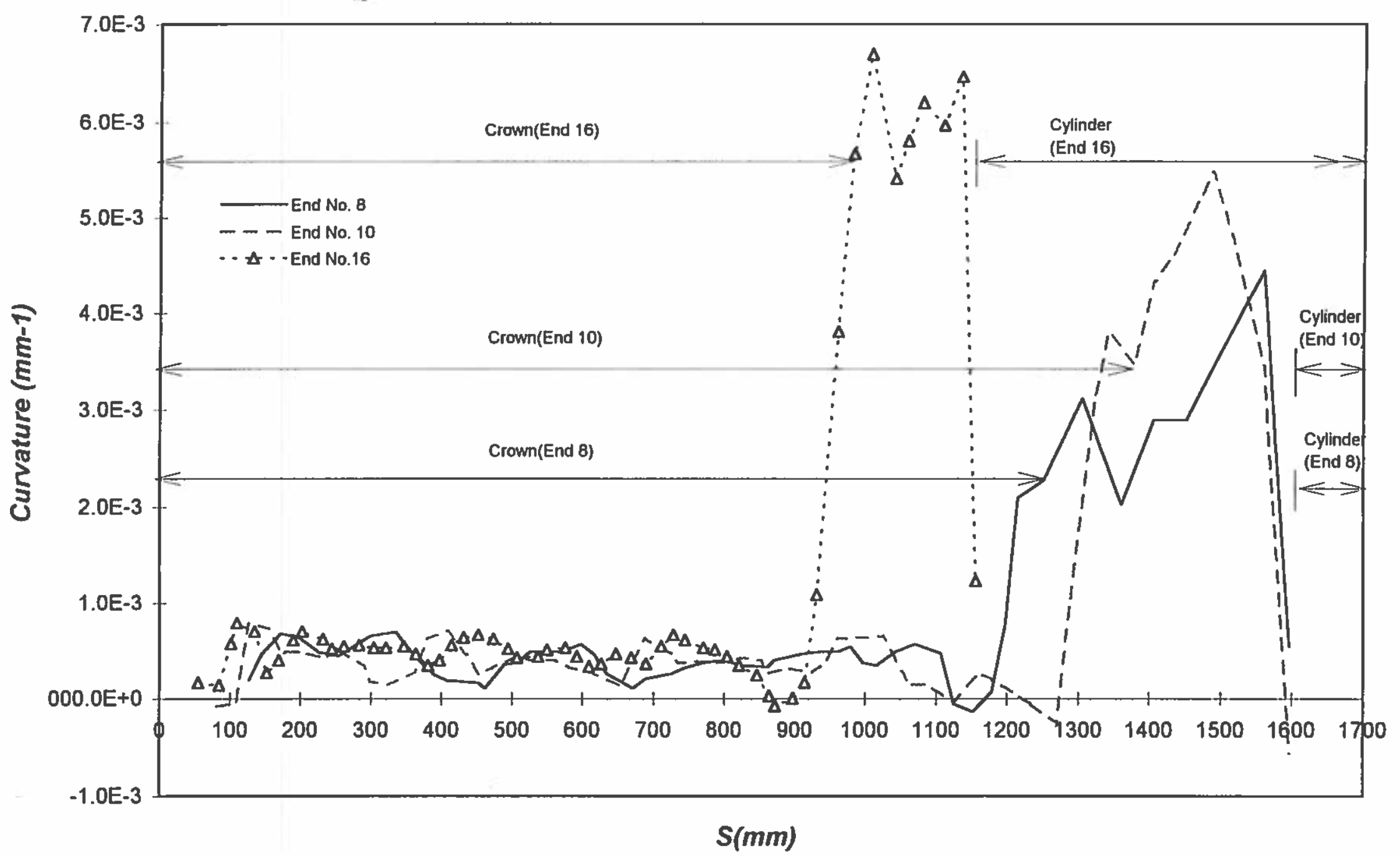


Tafreshi, A. Apr. 1997 In : International Journal of Pressure Vessels and Piping. 71, 1, p. 77-88 12 p.

Fig. 5 Thickness variations of ends 8,10 and $16(1)$

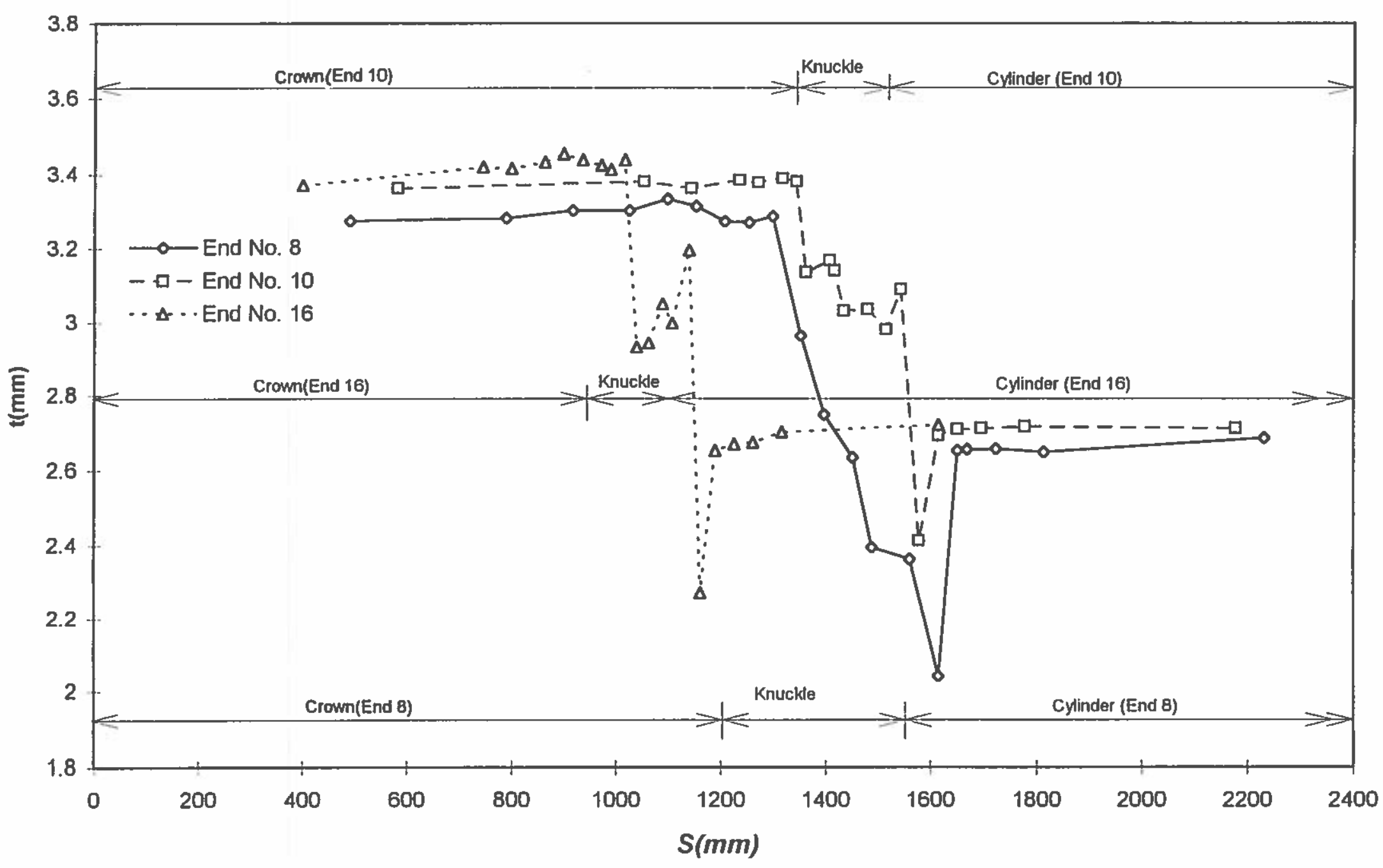


Tafreshi, A. Apr. 1997 In : International Journal of Pressure Vessels and Piping. 71, 1, p. 77-88 12 p.

Fig. 6 Perfect and imperfect geometries of ends 4, 8 and 16

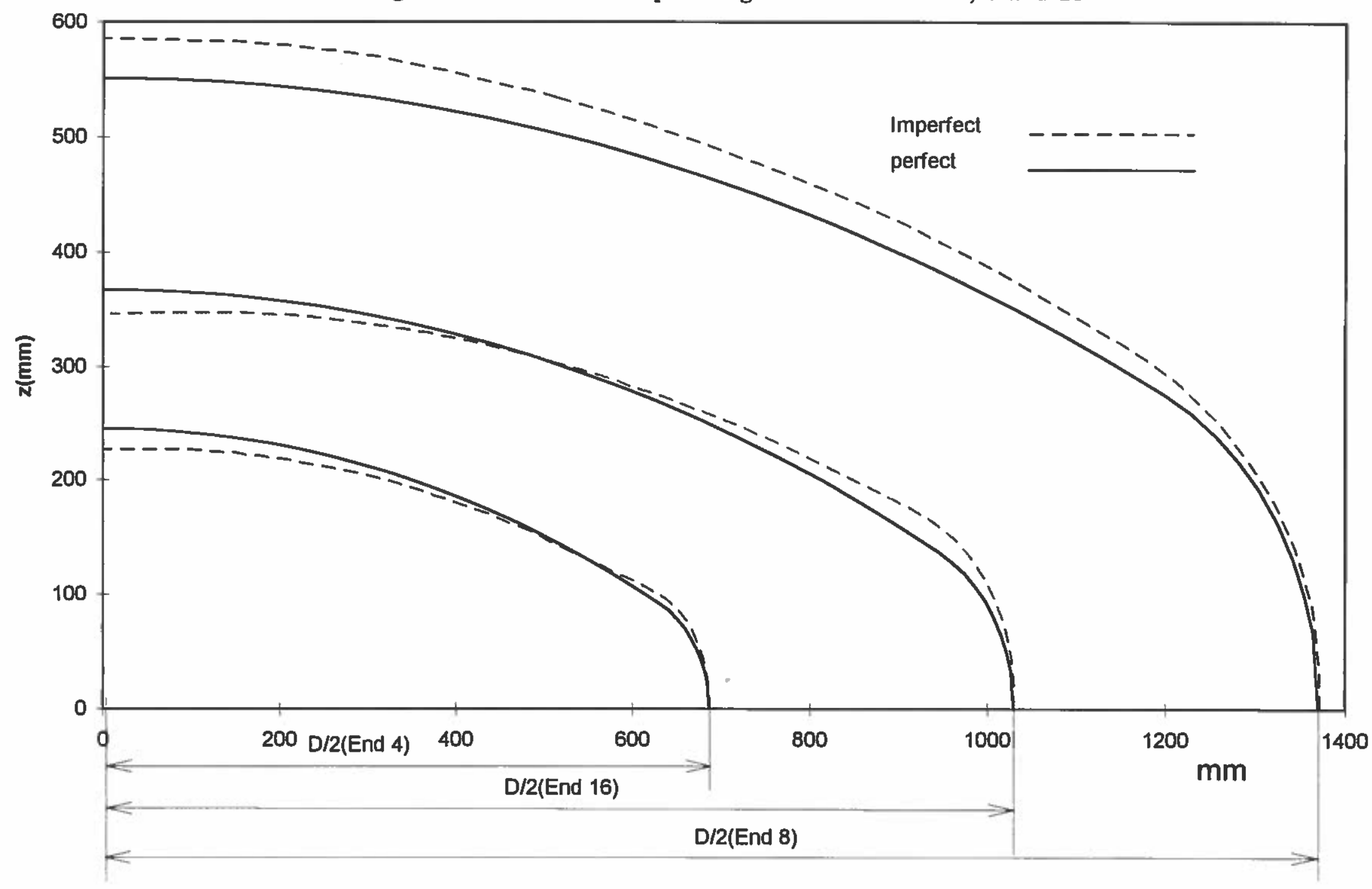


Tafreshi, A. Apr. 1997 In : International Journal of Pressure Vessels and Piping. 71, 1, p. 77-88 12 p.

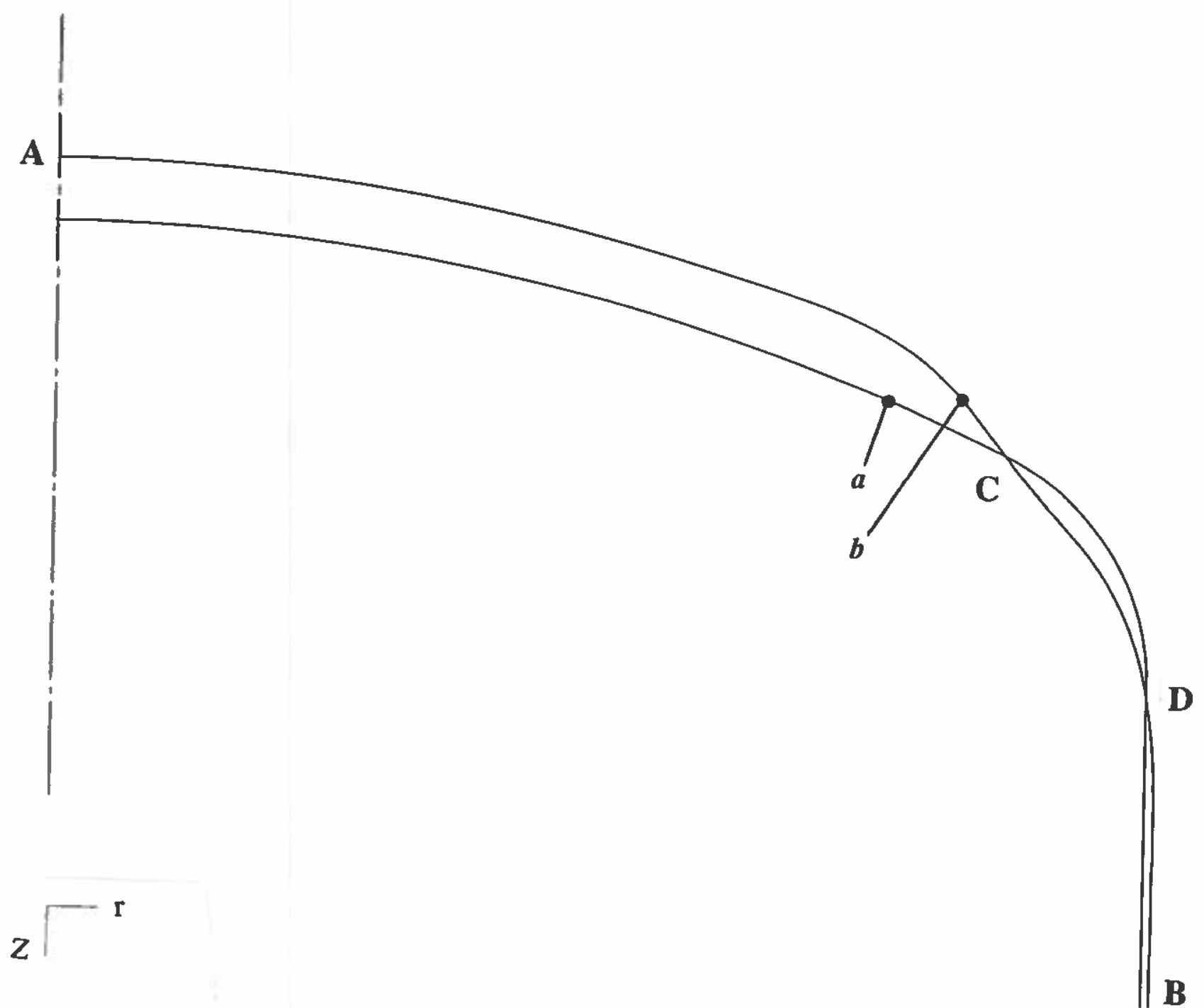

Fig. 7 Exaggerated deformed geometry of a quarter of a perfect end closure under internal pressure a) original geometry b) deformed geometry 
Tafreshi, A. Apr. 1997 In : International Journal of Pressure Vessels and Piping. 71, 1, p. 77-88 12 p. Chart 1

Fig. 8 Inner surface meridional and outer surface circumferential stress indices of perfect end 4 for linear and non-linear geometric analysis

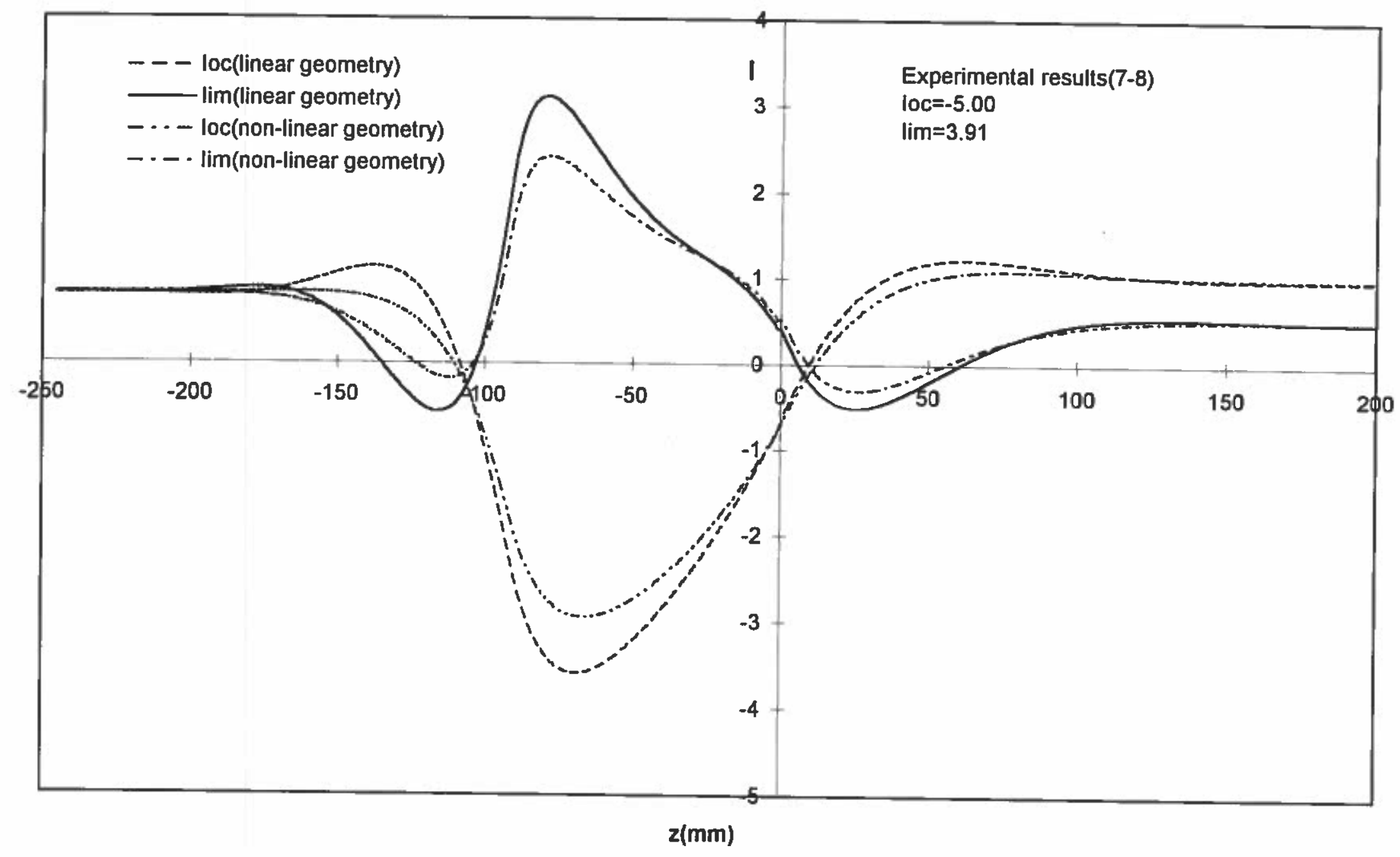


Tafreshi, A. Apr. 1997 In : International Journal of Pressure Vessels and Piping. 71, 1, p. 77-88 12 p.

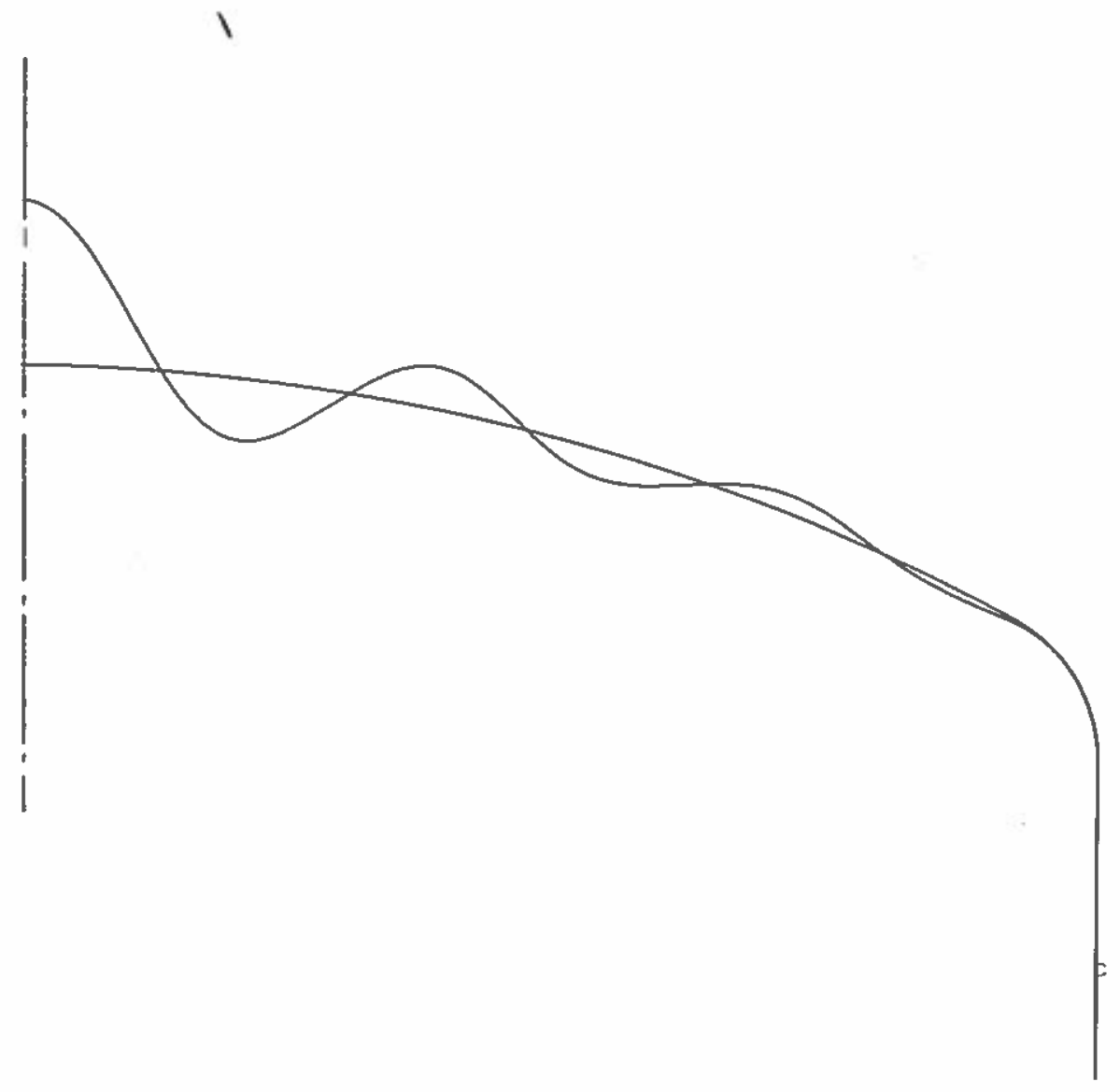

Fig. 9 Axi-symmetric buckling mode 
Tafreshi, A. Apr. 1997 In : International Journal of Pressure Vessels and Piping. 71, 1, p. 77-88 12 p.

Fig. 10 The effect of knuckle radius on the peak inner surface meridional stress index (Iim), $\left(D=54 ", t_{r} / D=0.00237, t_{c} / D=0.00193\right)$

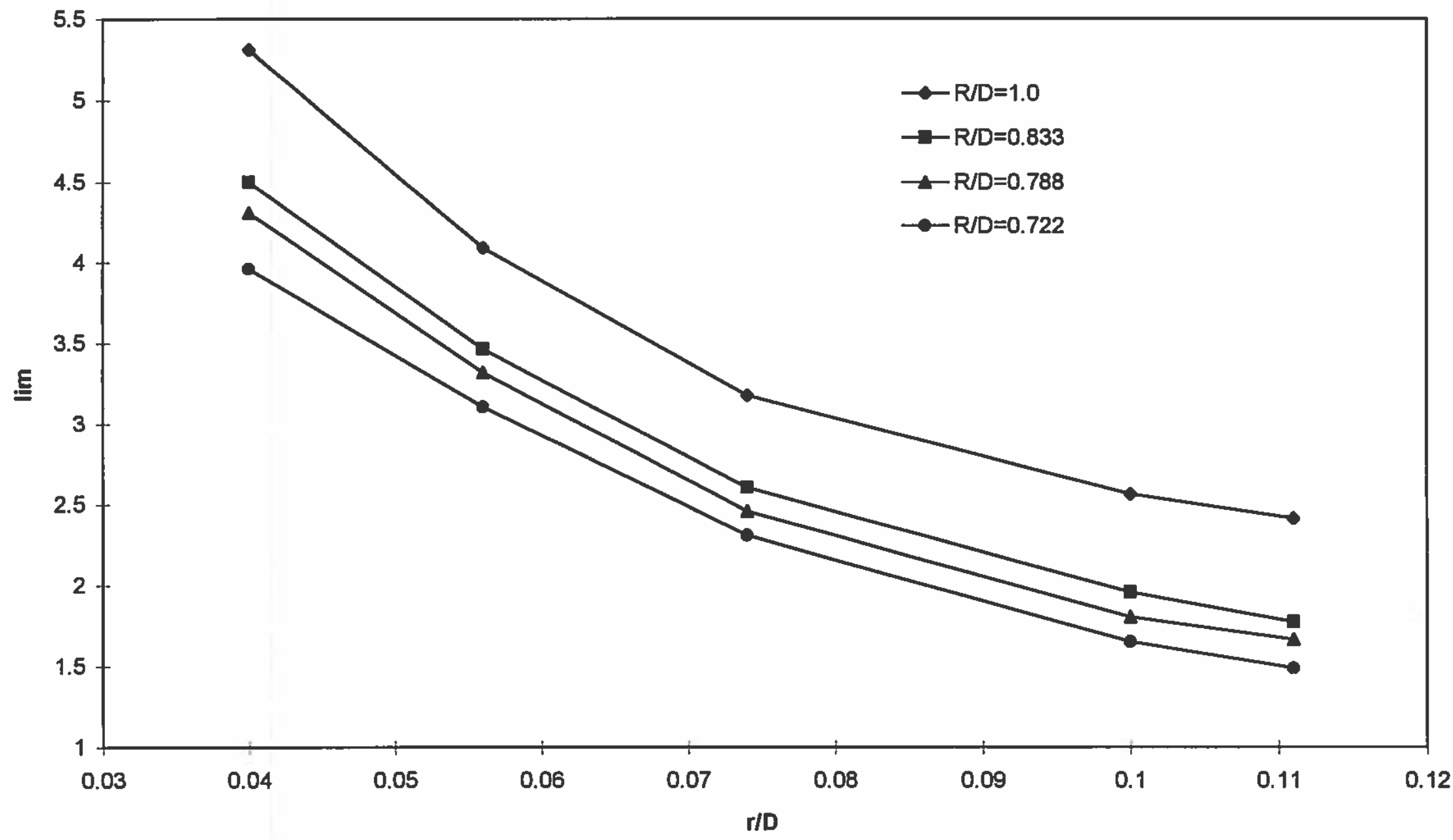


Tafreshi, A. Apr. 1997 In : International Journal of Pressure Vessels and Piping. 71, 1, p. 77-88 12 p.

Fig. 11 The effect of crown radius on the peak inner surface meridional stress index (Iim). $\left(D=54^{\prime \prime}, t / D=0.00237, t_{s} / D=0.00193\right)$

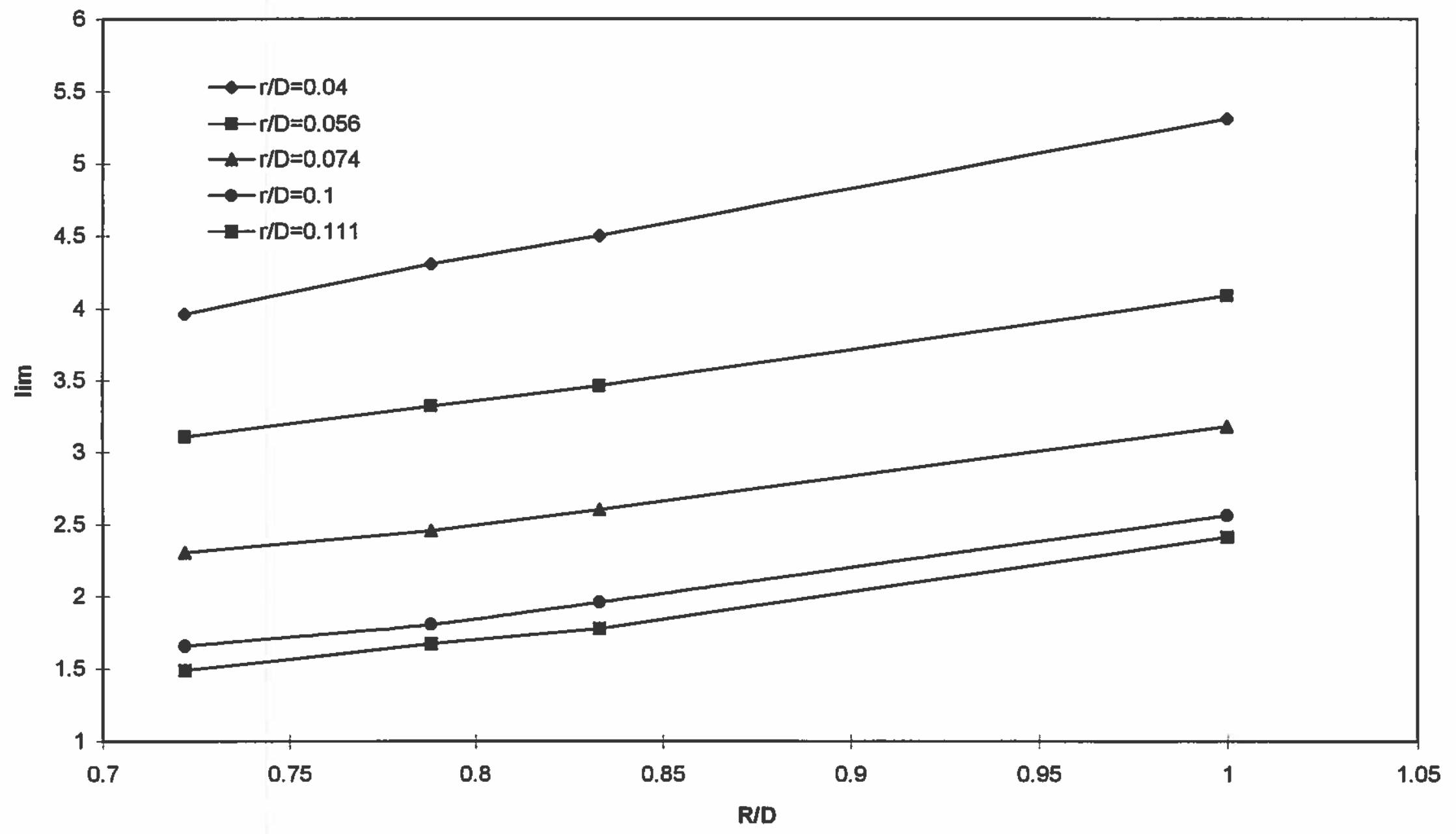


Tafreshi, A. Apr. 1997 In : International Journal of Pressure Vessels and Piping. 71, 1, p. 77-88 12 p.

Fig. 12 The effect of knuckle and crown radii on critical buckling pressure(Pcr), $\left(D=54^{\prime \prime}, t_{。} / D=0.00237, t_{\varepsilon} / D=0.00193\right)$

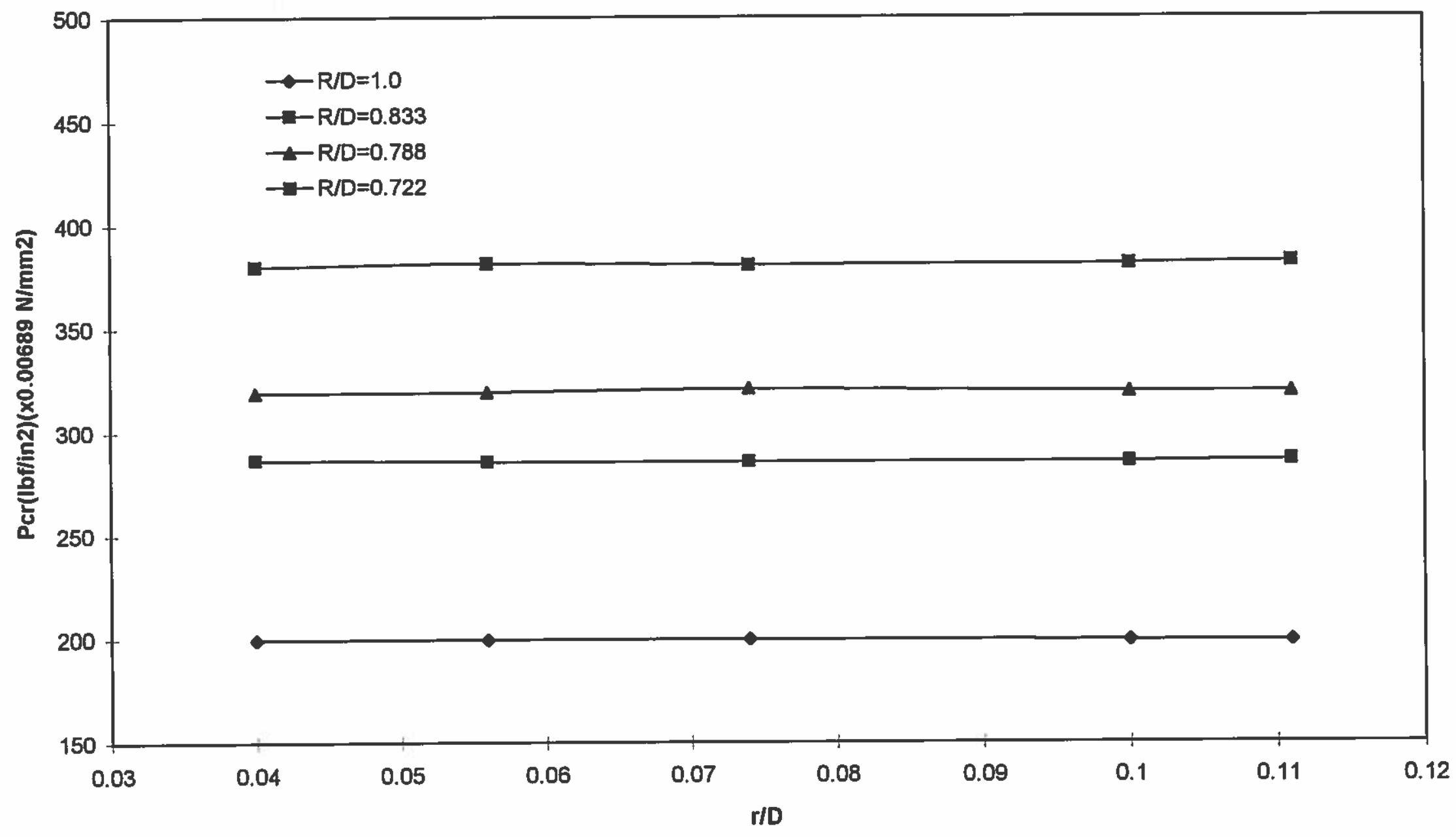


Tafreshi, A. Apr. 1997 In : International Journal of Pressure Vessels and Piping. 71, 1, p. 77-88 12 p.

Fig. 13 Distribution of inner surface meridional and outer surface circumferential stress indices of real and perfect ends 4

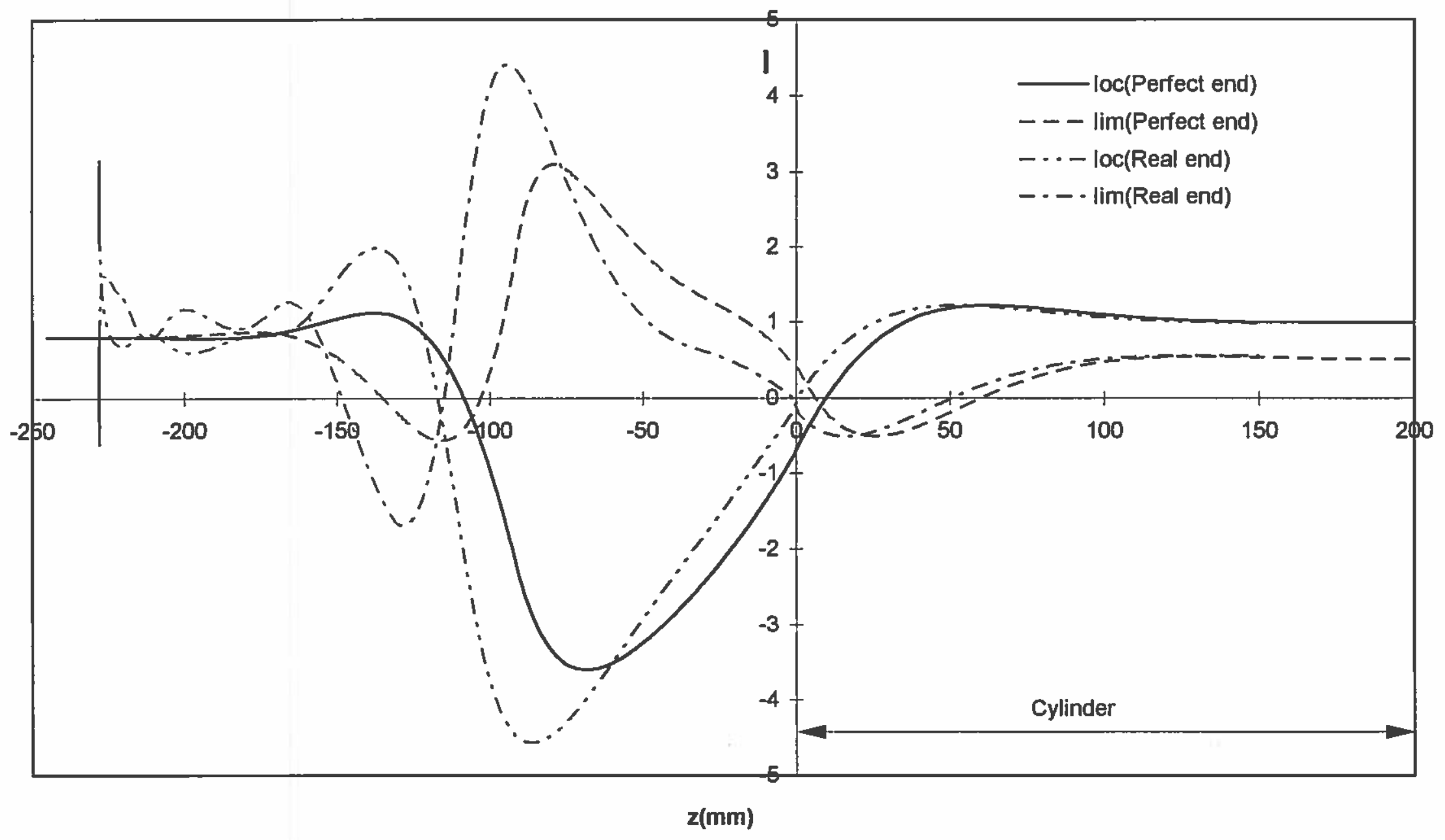


Tafreshi, A. Apr. 1997 In : International Journal of Pressure Vessels and Piping. 71, 1, p. 77-88 12 p.

Fig. 14 Distribution of inner surface meridional and outer surface circumferential stress indices of real and perfect ends 8

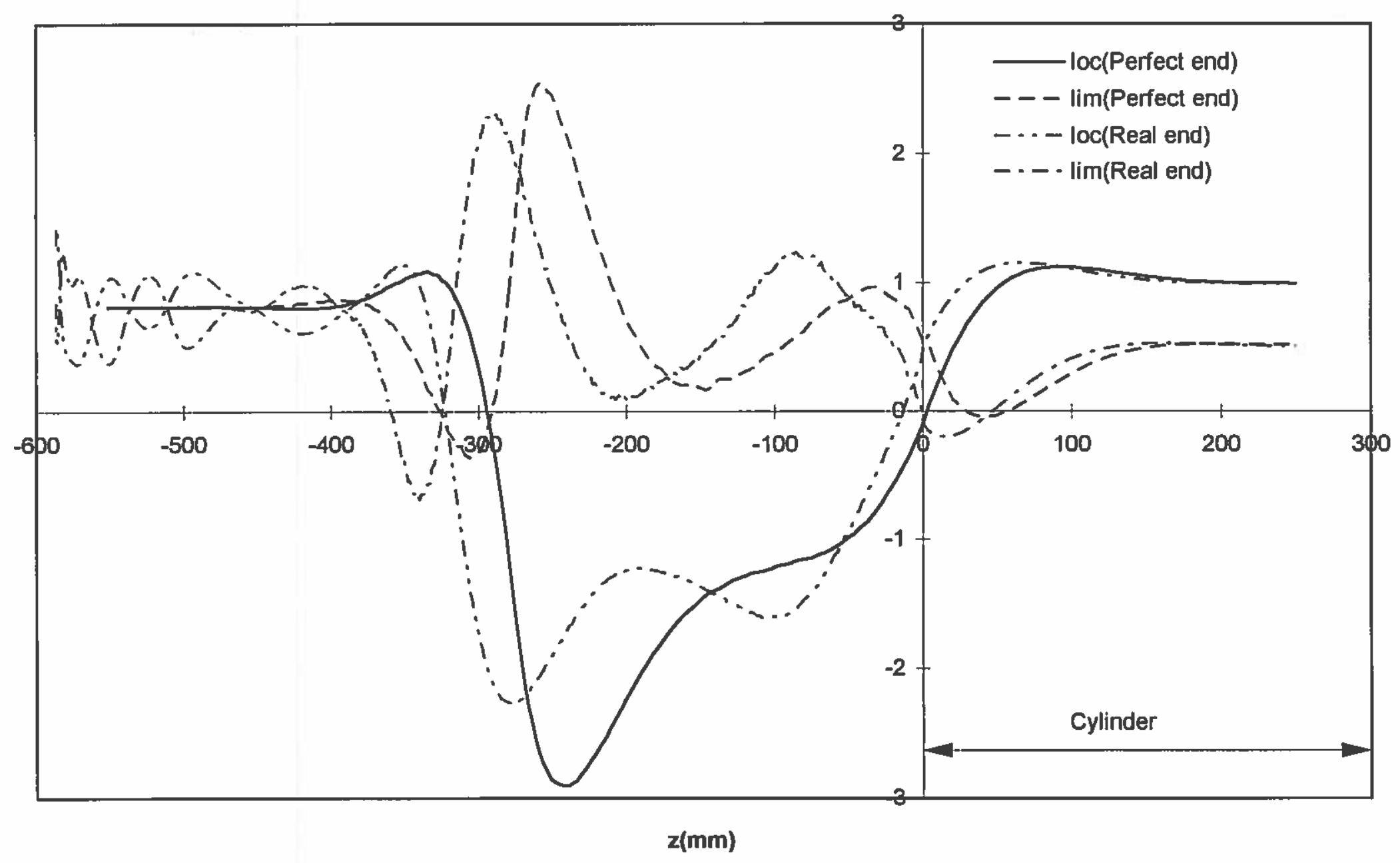


Tafreshi, A. Apr. 1997 In : International Journal of Pressure Vessels and Piping. 71, 1, p. 77-88 12 p.

Fig. 15 Distribution of inner surface meridional and outer surface circumferential stress indices of real and perfect ends $\mathbf{1 6}$

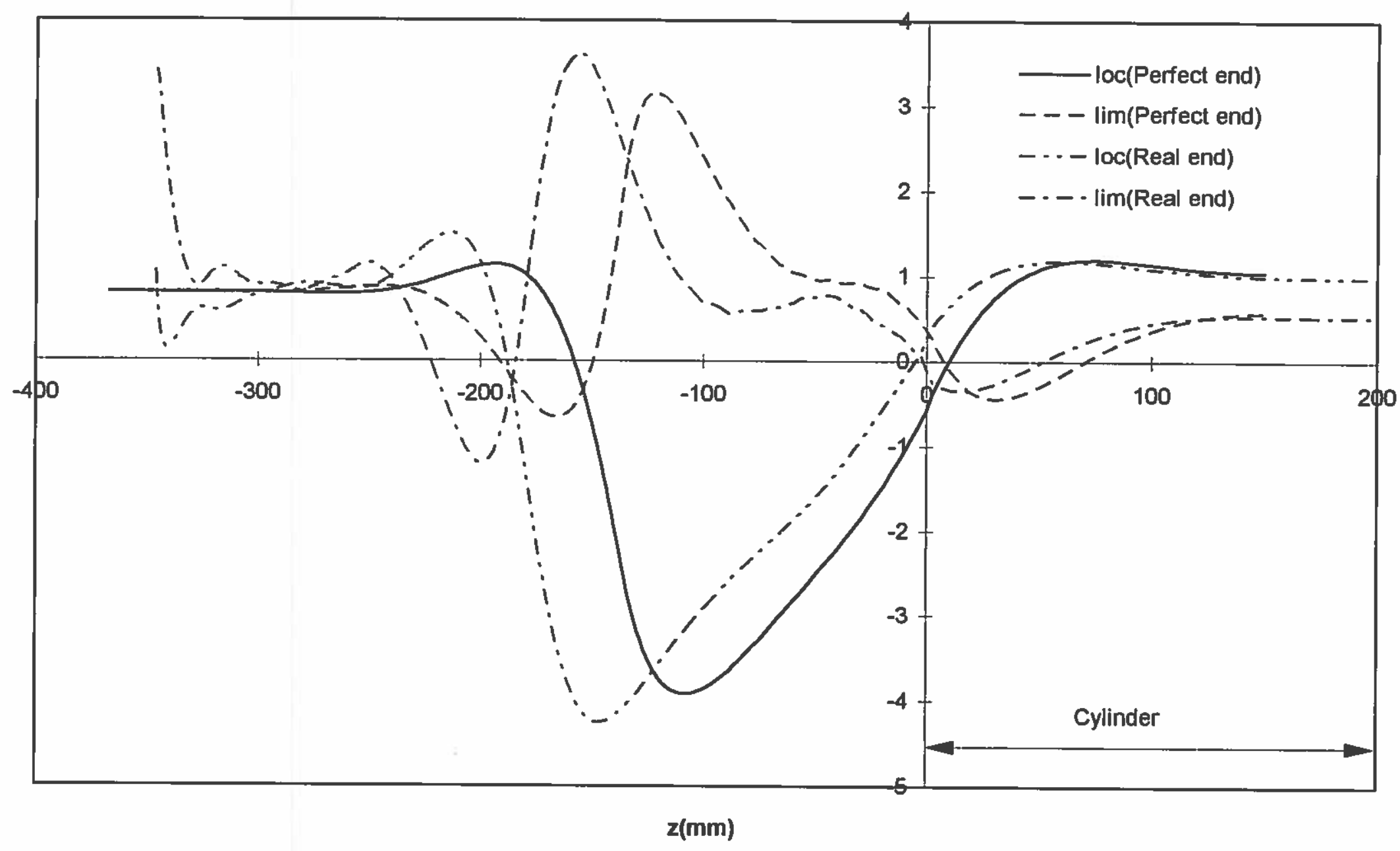


Tafreshi, A. Apr. 1997 In : International Journal of Pressure Vessels and Piping. 71, 1, p. 77-88 12 p.

\section{Fig. 16 Pressure vs deflection of perfect and real ends 4}

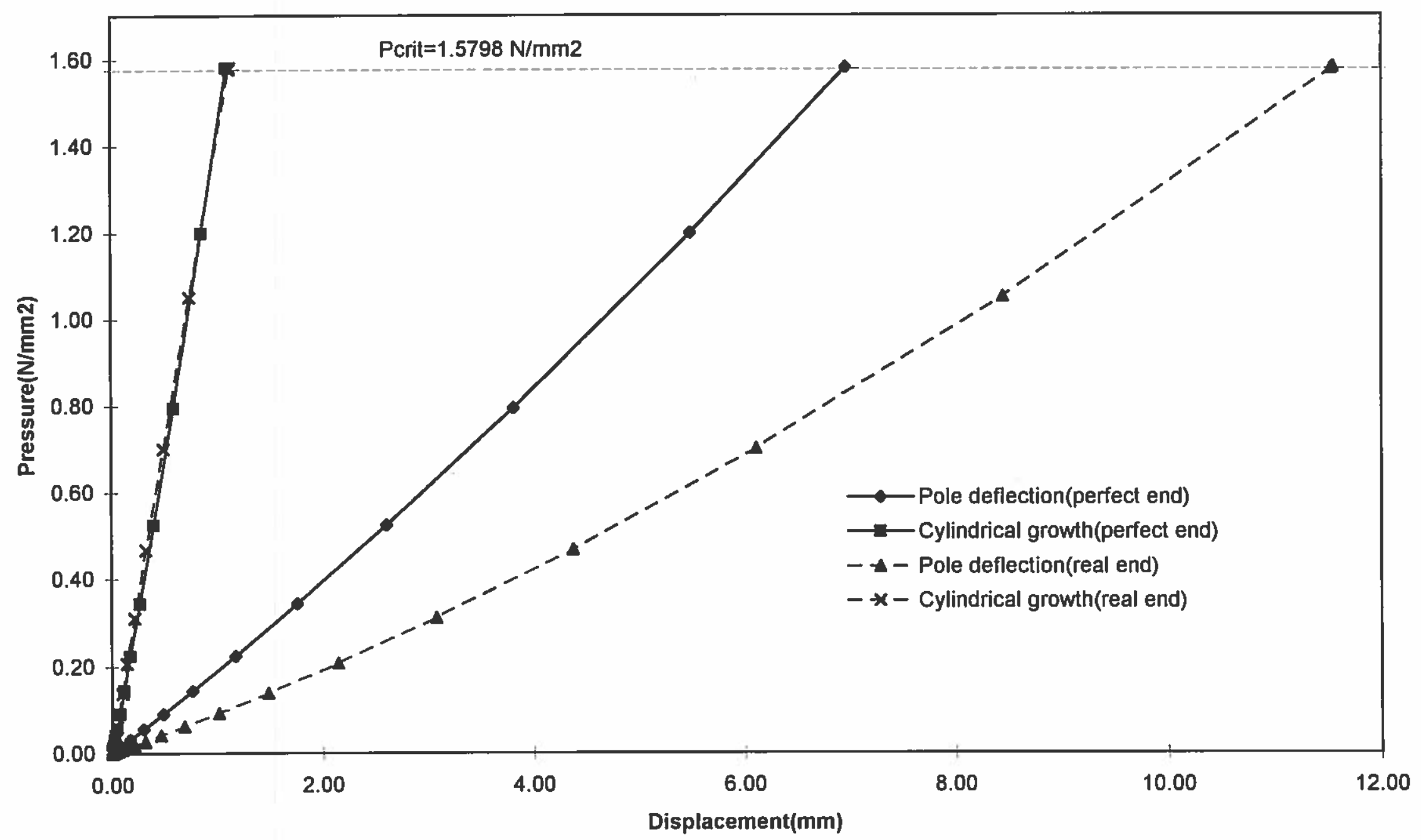

Page 1 